\title{
Shading: a traditional method of microclimate manipulation
}

\author{
C. J. Stigter
}

Section Agricultural Physics, Physics Department, University of Dar es Salaam, P.O. Box 35063, Dar es Salaam, Tanzania, traditional farming

Received 19 September 1983; accepted 9 February 1984

Key-words: shading, microclimate, Tanzania, traditional farming

\section{Summary}

Microclimate management and manipulation are among the methods which have traditionally been employed on small plots in low-input agriculture. This paper deals with methods smallholders employ to shade soil, seedlings, plants and crops to protect them from environmental stresses and to improve their yield capacity. Specific examples collected from Tanzanian practice are described as evidence of today's use of shading methods in traditional farming.

\section{Introduction}

As has been shown most illustratively by Wilken (1972) traditional farmers deliberately modify or use crop climate for protection and improvement purposes. Such management and manipulation has hardly been studied as a field of applied micrometeorology. This paper wants to be an introduction for such studies, to increase the role of micrometeorology in rural development in the third world (Bernard, 1974; Esman, 1980).

The shading of soil, seedlings, plants and crops may result in a wide range of diverse intentional or unintentional effects. These include decrease of evaporation as well as matching growth and available nutrients, preventing serious water and nutrient stresses respectively. A decrease in plant, animal or soil temperature in day time may be achieved as well as an increase of these temperatures at night. Shading may provide protection against rain, hail and wind impact and consequential damage as well as lead to a decrease of air flow, influencing transport of water vapour, heat and $\mathrm{CO}_{2}$ from or to the surface concerned. Shading can be employed to reduce weed growth as well as to prevent sun scorch.

Some uses of shade came together with the introduction of new crops in the course of time. Especially where such techniques were familiar to the farmers, old- 


\section{J. STIGTER}

er and newer uses of shading merged to give rise to present day's practices. It is almost impossible to differentiate in today's practices between traditional, indigenous components and imported ones. We therefore confine ourselves to a description of the present state of shade management in traditional food and cash crop growing. Some of the information presented here was obtained in a recent contest we organized for the general public in Tanzania to collect information on traditional microclimate management and manipulation methods.

\section{Types of shading}

Natural shading is by definition provided by natural means such as trees, high crops (for example in intercropping and multi-storage gardens), shrubs or plants, creeping crops and grasses. Falling leaves and stubble left in the ground must be regarded as natural shading mulches. One type of artificial shading is provided by mulches of organic and inorganic origin, layers of material on the surface of the soil with physical properties different from those of the soil. These mulches consist of material collected by the farmer at the field concerned or elsewhere and spread over part or all of the soil surface. In traditional farming organic materials such as stems, branches and twigs, large leaves (as from bracken and bananas), grasses, left-overs from weeding, pruning or harvesting (such as sisal waste and wheat straw), pulp, saw dust and wood shavings, decomposed materials and manure from dung are applied. Stone chippings and ash are the only examples of inorganic materials applied traditionally if tillage, establishing a layer of soil different from the sub-soil, is excluded from the definition of creating a mulch. The inorganic materials of crucial importance in the horticulture and cash crop growing of the developed world find little application. The recent non-traditional use of black polyethylene in sisal and pineapple growing is an exception.

Another type of artificial shading is applied in the form of roofing. It may simply consist of large broad leaves stuck in the ground and bent over seedlings to provide shade. But even more common is the use of a raised roof on poles, a framework or cage covered with cloth, lattice, grass, branches etc. This method is used in nurseries and seed-beds but also in grain or tobacco drying. The density of the roofing material is very often reduced in the course of seedling growth to harden them before transplanting. In contrast to mulching, roofing allows much more air flow. Mulches create a layer in which air can be assumed to be largely stagnant or slowly moving by what physicists call convection. When employing roofing with cage structures or bent leaves as a source of shade, air movement between shade and plant may be reduced, but is still appreciable. This results in a lasting transfer to the atmosphere of $\mathrm{CO}_{2}$ at night and, more importantly, of heat (advection excluded) and water vapour in day time, and a transfer from the atmosphere of heat at night and $\mathrm{CO}_{2}$ in day time. The above difference in air flow also exists between mulches and open shades in natural shading.

Other shading techniques involve the covering of single plant or fruit surfaces, as for example in protecting tea bushes, pineapples and bundles of cut sisal from sun scorch. 


\section{Effects of shading}

In microclimate management and manipulation of shade we are interested in the modification of the energy balance at a soil surface, a crop canopy, a nursery surface or individual plant organs like stems, leaves, flowers or fruits. Solar radiation is the driving force of the energy balance. Shading implies reflection and absorption of excess solar radiation, transmitting only the requirements of soil, seedling, plant or crop. This transmitted radiation is used for photosynthesis, heating and evaporation (including drying).

It is well known that under very many tropical conditions, especially outside the humid tropics, high radiation loads are received at the earth's surface. The loads are much in excess of the energy requirements of photosynthesis and radiation requirements of other physiological processes performing at optimum rate. Evaporation from plants and wet soil and their temperatures in dry conditions also tend to be higher under natural radiation than necessary or wanted. Reducing radiation loads is therefore very useful. Traditionally, farmers were well aware of the damage done by radiation to seedlings, young plants and crops in need of water. The harmful effects of the drying of the topsoil under windy conditions was also appreciated. In shifting cultivation, still an important practice in areas with abundant but poor land, some trees are left in freshly cleared terrain and remains of uprooted or slashed trees and plants are left on the surface. Only a closed vegetation starts to take care of its own shading requirements.

Any manipulation of radiation not only modifies the amount of radiation received but influences other terms of the energy balance. It affects the amounts of energy available for heating and evaporation. Long-wave (or thermal) radiation can in the open easily escape to a sky with low cloudiness. At high altitudes shading therefore gives protection against frosts and chilling effects. We have already mentioned influences on air flow and on heat and mass transfer as a consequence of reduced air movement. Indeed the whole microclimate is affected by the manipulation of one factor. Of course the traditional farmer is unaware of the cause-and-effect relationships which the science of micrometeorology has established at least qualitatively. But he is well acquainted with the consequences.

When applying mulches or roofing not only the aerial, radiation and soil climates are changed. Damage from wind and water erosion of the soil and from strong winds, big rain drops and hail to plant material are visibly reduced. When mulches from decomposing material, ash, manure, etc. are used, soil fertility is clearly improved. Moreover, microclimate modification is known to influence, beneficially or detrimentally, weed growth and the occurrence of other pests and diseases. Some crops appear to do better when sown and/or grown under a cover of vegetation (including another crop). Additionally the planting of more than one crop in one field safeguards against low yield of any given crop and may result in other advantages of diversification. Shade trees may improve drainage conditions of soils. Finally they provide shade for the peasant as well.

Measures to reduce shade are of course also known. From clearing forests to spacing and pruning or thinning canopies, the intention is to increase the amount of 


\section{J. STIGTER}

radiation reaching the lower parts of vegetation or the soil. This reduces the competition for light and nutrients and gives a better light distribution and a lower humidity. The severity of some pests and diseases is reduced under such conditions. Use of north/south rows to decrease mutual shading is also traditionally applied.

\section{Examples from Tanzania}

One of the most interesting examples of shade management in Tanzania by natural means comes from a district in Iringa region. A huge tree with a life measured in centuries, which typically covers about one acre, is used to provide shade to soil and crops in the periods they need it most. The tree sheds its leaves in April and gets new ones in November. Therefore maize and millet are planted between November and January, making use of the shade. But from April onwards radiation increases and ripening takes place in June when tree leaves are absent, so that the seeds can dry on the plant, before harvest. Wheat and beans are grown in March and April, ripening in September/October, also fully drying before harvest. Fruits are grown between December and March. Potatoes, coffee, pyrethrum, cabbages, sunflower and onions all do well around these trees. Its shed leaves form a mulch, decompose and release plant nutrients. Evaporation from the rooting zone of the crops is reduced. Soil erosion and wind speed are reduced as well. The trees protect the crops and their environment at the required times.

There is much debate in the literature on the traditional uses of shade with coffee and tea crops (fig. 1). Combining the useful reviews of Acland (1971) with the in-

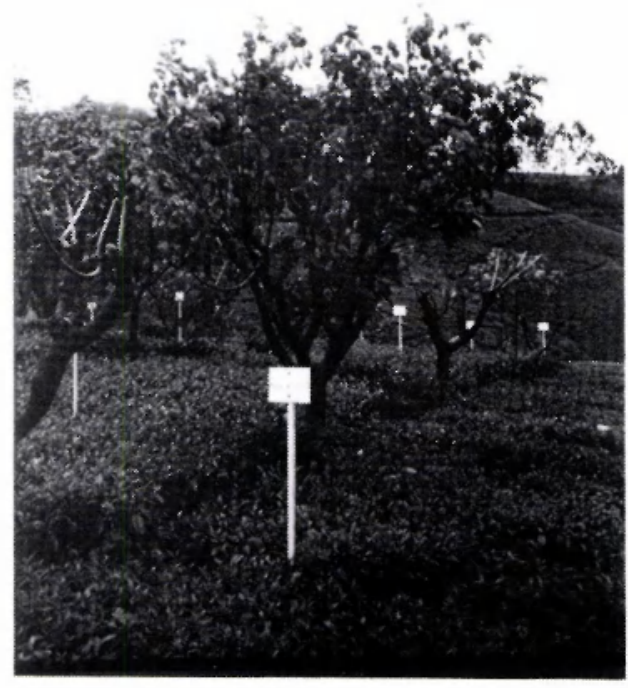

84
Fig. 1. An example of light shade in tea growing. (Photo: Department of Tropical Crop Science, Agricultural University, Wageningen) 
formation we obtained from our contest, the following holds. In tea growing, seedlings and cuttings need shade almost everywhere, but hardening is applied towards transplanting time. If they are well hardened no shade is necessary after planting. Only on poor soils does shade increase tea yields, matching availability of nutrients with reduced photosynthetic rate. In the growing of Arabica coffee the problems are more complex. Shade trees lead to yield reduction, compete for nutrients and encourage certain pests and diseases. However, other pests and diseases are biologically discouraged by shade. In the seedling, flowering and ripening stages clear benefits are derived from the presence of shade trees. At high altitudes protection against night frost is provided. Combining this with the substantial economic benefits of growing coffee under bananas (a technique widely employed in Tanzania), it becomes understandable why the majority of smallholders still prefer to grow their coffee under moderate shade. Additionally it is interesting to note that banana growers in some regions of Tanzania are extremely shade-conscious in regard to soil as well as to stem and leaves (Fig. 2).

Artificial shading of transplanted cabbage, with big broad leaves, and of transplanted coffee (if no trees are available) and mangoes by a raised shade is practised. On the farm, overdrying of grain might be prevented in the same way. Shade drying under mulch of tobacco leaves has been reported as well as natural shade drying of wattle (Acacia mearnsii) in relatively wet weather. Intersowing and-cropping such as wattle with maize, cowpeas with other food crops, annual crops in banana with coffee fields, maize with tomatoes, and cover or food crops in sisal are at least in part due to deliberate shade manipulation.

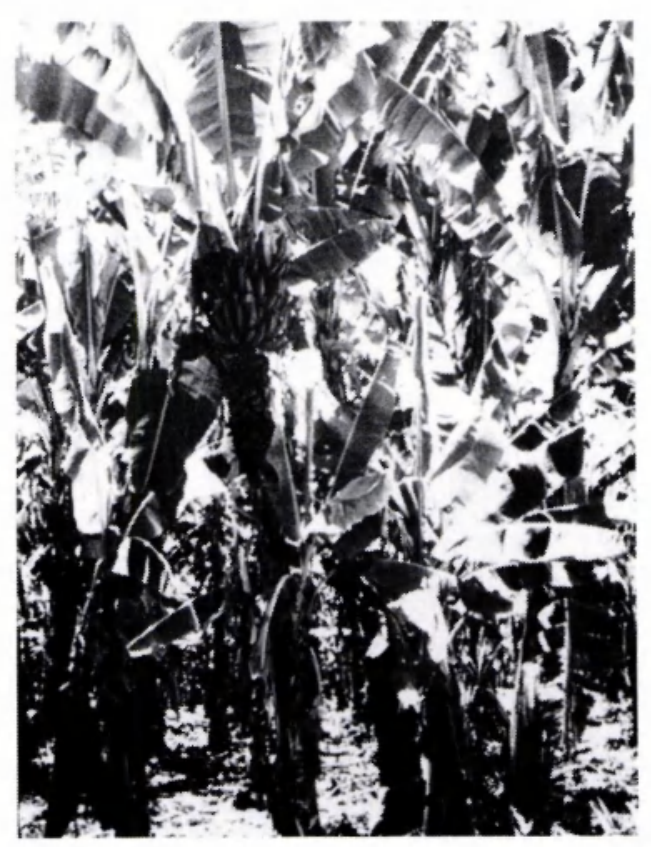

Neth. J. agric. Sci. 32 (1984)
Fig. 2. Characteristic banana plantation in Tanzania. The soil is covered by a mulch of leaves which receives additional shade from the crop. (Photo: Department of Tropical Crop Science, Agricultural University, Wageningen) 


\section{Final remarks}

The above examples all show the surprising variation of traditional methods of shade management. We are not suggesting that all these practices were and are common to all traditional farmers. If that had been the case, traditional agriculture in the third world would generally have produced higher yields and living conditions would have been better. Soil erosion would not have taken away so much fertile soil and cash crop trials on denuded soil would not have failed. The knowledge was slowly acquired but social, economical and political conditions often prevented wider and more intensive use of these traditional practices. Attention in local research for traditional methods will surely contribute to an improvement of this situation.

\section{Acknowledgements}

The author thanks Mr G. Kalekola and Mr R. M. Kainkwa for their assistance in translating and cataloguing of more than 100 essays by Tanzanians submitted in a contest. He is also grateful to all those participants for sharing their knowledge with him. He thanks Dr M. Friedeberg for improving the English of this paper.

\section{References}

Acland, J. D., 1971. East African crops. Rome, FAO and Longman, 252 pp

Bernard, E., 1974. Agrometeorology and agricultural production. FAO-Background Paper AGPE/ MISC. 5, 9 pp. Rome, FAO.

Esman, M. J., 1980. The role of scientific research in rural development. In: R. C. Staples \& R. J. Kuhr (Eds.), Linking research to crop production, p. 209. New York, Plenum Press.

Wilken, G. C., 1972. Microclimate management by traditional farmers. Geographical Review 62, 544 566. 